\title{
Transition metal sulfides on zeolite catalysts for Selective Ring Opening
}

\author{
N. Catherin, ${ }^{a}$ E. Blanco, ${ }^{a}$ D. Laurenti, ${ }^{a}$ L. Piccolo, ${ }^{a}$ F. Simonet, ${ }^{a}$ C. Lorentz, ${ }^{a}$ E. Leclerc, ${ }^{a}$ V. \\ Calemma, ${ }^{\mathrm{b}} \mathrm{C}$. Geantet. ${ }^{*}$ \\ a Université de Lyon, Institut de Recherches sur la Catalyse et l'Environnement de Lyon \\ (IRCELYON), UMR5256 CNRS-UCB Lyon 1, 2 Avenue Albert Einstein, 69626 Villeurbanne \\ Cedex, France. \\ ${ }^{b}$ Eni S.p.A., DOW R\&D Division, Via F. Maritano 26, 20097 San Donato Milanese, Italy. \\ * corresponding author \\ E-mail address : christophe.geantet@ircelyon.univ-lyon1.fr
}

\begin{abstract}
Bifunctional catalysis combining acidic catalysts and sulfide active phases is usually related to hydrocracking catalysts which balances the hydrogenation function of a NiMo (NiW) alumina supported sulfide catalysts and the acidic function of a zeolite. The discovery of sulfurresistant catalysts for selective ring opening (SRO) is an important challenge for refiners, considering the future legislation on cetane index of diesel fuels. In the present work, we studied the properties of various transition metal sulfides (TMS) supported on Y zeolite in gasphase decalin hydroconversion at high hydrogen pressure $(5 \mathrm{MPa})$ in the presence of $0.8 \%$ $\mathrm{H}_{2} \mathrm{~S}$ concentration. This screening shows high activities for noble metal based sulfides with a mechanism which proceeds by skeletal isomerization induced by the zeolite. Catalytic activity was improved by the use of ternary sulfides such as $\mathrm{Ni}_{1-x} \mathrm{Ru}_{x} \mathrm{~S}_{2}$ or $\mathrm{NiRh}_{2} \mathrm{~S}_{4}$ on $\mathrm{Y}$ zeolites. High decalin conversion levels can be reached below $250^{\circ} \mathrm{C}$ with more of $20 \%$ of ring opening products and thanks to the use of comprehensive GC, a detailed mechanism of the SRO of decalin is given.
\end{abstract}

\section{Introduction}

Bifunctional catalysis involving transition metal sulfides and acidic supports (silica alumina or zeolite) is usually dealing with hydrocracking, process which aims to convert a heavy feedstock (Vacuum Gas Oil) into lighter fuels [1,2]. However, considering the increasing constrains on cetane index in diesel fuels, another important challenge for refiners, addressed with bifunctional catalysts, is the selective ring opening (SRO) of polyaromatic compounds and its application to the conversion of Light Cycle Oil (LCO) type feedstocks [3]. In fact, SRO is a special case of hydroconversion for which carbon-carbon bond in a naphthene is to be broken without cracking [4]. This topic has been intensively investigated with noble metal based catalysts. By controlling the hydrogenolysis of noble metal (Ir) and the acidity of the support, efficient SRO systems were obtained [5-7]. However, their use required a preliminary deep desulfurization stage due to their lack of thioresistance. Therefore, the ideal catalytic system should be based on a thioresistant active phase which is typically the case of sulfide catalysts. Sulfides catalysts are therefore good candidates since they can work under several $\%$ of $\mathrm{H}_{2} \mathrm{~S}$. Few investigations have been made and 
in this field and they often suffer from analytical problems due to the complexity of the products mixture of $\mathrm{C}_{10}$ compounds [8]. In this domain, literature describes the conversion of tetralin or decalin with conventional NiMoS or NiWS sulfide catalysts deposited on various acidic supports such as $\mathrm{Zr}$ doped mesoporous silica [9], USY [10], $\mathrm{Al}_{2} \mathrm{O}_{3}$-USY mixture [11], silica alumina [12] or with $\mathrm{Al}_{2} \mathrm{O}_{3}$-USY mixtures promoted by $\mathrm{P}$ or $\mathrm{Ti}$ to modulate acidity [13].In the case silica alumina of various composition or doped with $\mathrm{F}$, at $350^{\circ} \mathrm{C}$, selectivity towards ring opening products remains below $15 \%$ whatever the conversion level (10-80\%) [12] and for mesoporous silica at $100 \%$ conversion, tetralin leads mostly to hydrogenated compounds and cracked products (60\%). In fact, tetralin was often used as reactant but it is rapidly hydrogenated into $\mathrm{C}$ (cis) and $\mathrm{T}$ (trans) decalin which further reacts. For USY based catalysts, at conversion levels close to $95 \%$ light paraffins and napthenes corresponds to nearly $40 \%$ of the products and ROP are claimed to be close to $30 \%$ [13]. Recently, we proposed to investigate new types of active sulfide phases and proposed $\mathrm{RuS}_{2} / \mathrm{Y}$ zeolite as a candidate for thioresistant ring opening catalysis. Known from the studies of periodic trends of unsupported catalysts as one of the most efficient hydrotreating TMS active phase $[14,15], \mathrm{RuS}_{2} / \mathrm{Y}$ zeolite exhibits interesting properties for ring opening of decalin below $300^{\circ} \mathrm{C}$. As compared to $\mathrm{HY}$ zeolite alone, the presence of RuS $_{2}$ improves stability and increases 10 times the rate of ring opening. However, RuS 2 does not seem to be able to catalyse the hydrogenolysis of endocyclic $\mathrm{C}-\mathrm{C}$ bonds and the acidity of the zeolite appears to govern the overall catalyst reactivity, $Y$ zeolite being considered as the most active one among several [16]. Therefore, in the present work, we attempted to investigate other TMS, such as noble metal based sulfides (Rh, $\mathrm{Re}, \mathrm{Ir}$ ) might exhibit properties close to RuS 2 . A selection of TMS candidates was also made from a bibliographic survey identifying catalysts which can break C-C bonds. Among the various volcano curves (e.g. nature of the metal sulfide versus activity) reported, some unexpected selectivity were observed. For instance, periodic trend performed on biphenyl hydrogenation evidences $\mathrm{C}-\mathrm{C}$ bond breaking for $\mathrm{V}$ and $\mathrm{Nb}$ sulfides [15]. However, $\mathrm{Nb}$ and $\mathrm{V}$ sulfide were not investigated considering the difficulties to perform sulfidation of this element on and oxide support. During hydrogenation of toluene, $\mathrm{Cr}_{2} \mathrm{~S}_{3}$ or $\mathrm{Ni}_{3} \mathrm{~S}_{2}$ on alumina are not active as noble metal sulfides but lead to isomerization and ROP products [17]. From the screening of TMS/HY catalysts, a detailed reaction mechanism of the isomerization and ring opening will be proposed. Furthermore, the literature has also demonstrated that ternary sulfides such as $\mathrm{Ni}_{x} \mathrm{Ru}_{1-x} \mathrm{~S}_{2}$ [18] or $\mathrm{NiRh}_{2} \mathrm{~S}_{4}$ [19] can exhibit synergetic effects and enhance hydrotreating properties. Therefore, we also attempted to prepare these ternary sulfide phases on $\mathrm{Y}$ zeolite and investigate their catalytic performances.

\section{TMS/HY preparation and characterization}

TMS/HY catalysts were prepared by incipient wetness impregnation (IWI) using the following precursor salts $\mathrm{Ru}\left(\mathrm{NH}_{3}\right)_{6} \mathrm{Cl}_{3}, \mathrm{NH}_{4} \mathrm{ReO}_{4}, \mathrm{RhCl}, \mathrm{Cr}\left(\mathrm{NO}_{3}\right)_{3} \cdot 9 \mathrm{H}_{2} \mathrm{O}, \mathrm{VOSO}_{4} \cdot \mathrm{xH}_{2} \mathrm{O}$ ( purchased from Sigma Aldrich), $\mathrm{H}_{2} \mid \mathrm{ICl}_{6} \cdot \mathrm{xH}_{2} \mathrm{O}$, (Strem chemicals), $\left.\mathrm{Ni}\left(\mathrm{NH}_{3}\right)_{6}\right] \mathrm{Cl}_{2}$ (Alfa Aesar) . The metal salts were dissolved in $2.5 \mathrm{ml}$ of distillate water and 2 grams of zeolite was added, targeted loading were in the range of 2-3 wt\%. a sample with a lower Ni loading (close to $1 \mathrm{wt} \%$ ) was also prepared for getting atomic loadings close to those of noble 
metals. The HY zeolite used (Alfa Aesar, 45866) had the following characteristics: $S_{\text {BET }}$ $=781 \mathrm{~m}^{2} / \mathrm{g}$, porous volume $0.29 \mathrm{~cm} 3 / \mathrm{g}$, Si/Al atomic ratio=2.6, $1.8 \mathrm{wt} \% \mathrm{Na}$.

The mixture was matured for $8 \mathrm{~h}$ at room temperature and then was dried at $100{ }^{\circ} \mathrm{C}$ overnight. Catalysts were pre-sulfided under a 15 vol\% $\mathrm{N}_{2} / \mathrm{H}_{2} \mathrm{~S}$ gas flow with a total flow rate of $4 \mathrm{l} / \mathrm{h}$ at atmospheric pressure. The sulfidation temperature was raised at $10{ }^{\circ} \mathrm{C} / \mathrm{min}$ up to $400{ }^{\circ} \mathrm{C}$ and kept constant for $4 \mathrm{~h}$. During the cooling of the reactor (below $200^{\circ} \mathrm{C}$ ), the excess of $\mathrm{H}_{2} \mathrm{~S}$ was purged by flowing pure nitrogen. The sulfide catalysts were transferred from the reactor to vials under inert atmosphere (argon) and stored under argon.

Table 1 summarizes the characteristics of the series of TMS/HY catalysts and Table 2 the characteristics of the ternary sulfides on HY catalysts. A ThermoScientific Flash 2000 analyzer was used to determine $S$ contents. Other elemental analyses (metals) were performed by ICP-OES, after dissolution of the samples in acidic solutions, using an Activa apparatus from Horiba Jobin Yvon.

High-resolution transmission electron microscopy (TEM) was performed with a $200 \mathrm{kV}$ JEOL 2010 ( LaB $_{6}$ filament) microscope with point-to-point resolution of $0.195 \mathrm{~nm}$, and equipped with a LINK-INCA energy dispersive X-ray (EDX) analyzer. Thin cuts were made by embedding the freshly sulfide catalysts in an epoxy resin and prepared by ultramicrotomy. Ultrathin slices (10 to $50 \mathrm{~nm}$ ) of sample grains were examined. Results are summarized in Figure 1 shows the particles observed, their size distributions and provides S/M ration determined by EDX. Re sulfide is sensitive to electron beam [20] and not investigated by TEM. In average, the noble metal based catalysts exhibit small nanoparticles in the range of 1.5-2.8 $\mathrm{nm}$ average size; large particles are observed in the case of NiSx. These TMS present a nearly spherical shape. Due to its crystallographic properties, rhombohedral $\mathrm{Cr}_{2} \mathrm{~S}_{3}$ forms rather large plate-like particles as observed by Figure 2 [21,22].

The acidity of the catalysts was analyzed by Fourier-Transform infrared spectroscopy (FTIR) of adsorbed pyridine at various desorption temperatures. The concentrations of Brönsted and Lewis acid sites after desorption at 150,250 and $350{ }^{\circ} \mathrm{C}$ were calculated using the extinction coefficients $\varepsilon_{\mathrm{BA}}(1.67)$ and $\varepsilon_{\mathrm{LA}}(2.22)$ determined by Emeis et al. ${ }^{23}$

As compared to the zeolitic support alone, the introduction of the TMS generally reduces the Brönsted acidic site (BAS) content and strength except in the case of RuS 2 with an increase of BAS and with $\mathrm{Cr}$ sulfide where a high content of Lewis site was found. This sulfide belongs exhibit a low M-S bond strength [21] and the lamellar particles can be easily reduced at the surface to generate Lewis sites. For the variations observed on the other sulfides, we do not have yet any clear explanation. The quantification of BAS sites and the evolution of the acid strength with increasing desorption temperature is given on Figure 4.

The characterization of the ternary sulfides will be given in section 5 .

\section{Catalytic performances of TMS/HY catalysts}


The catalyst performances were evaluated in gas-phase decalin hydroconversion in the presence of $\mathrm{H}_{2} \mathrm{~S}$ using the high-pressure flow-fixed bed set-up already described in refs. $[11,16]$. Typically, $19 \mathrm{kPa}$ of decalin were introduced by flowing $\mathrm{H}_{2}$ through a separator/ condenser system and mixed with a secondary flow of $10 \% \mathrm{H}_{2} / \mathrm{H}_{2} \mathrm{~S}$ leading to a final concentration of $0.8 \%$ of $\mathrm{H}_{2} \mathrm{~S}$. A total pressure of $5 \mathrm{MPa}$ was maintained with a back pressure regulator. The space velocity was adjusted by varying proportionally the flow of each gas (WHSV ranging from 0.25-3.75 $\mathrm{h}^{-1}$ ). The stainless steel reactor with an inner Pyrex tube was filled with 100-200mg of catalyst powder and $50 \mathrm{mg}$ of crushed quartz. Reaction was performed for 3-5 days in a temperature range of $220-380^{\circ} \mathrm{C}$. GC Analysis was performed on line using with a Agilent CP-Sil Pona column (150 $\mathrm{m} \times 250 \mu \mathrm{m} \times 1 \mu \mathrm{m}, \mathrm{H}_{2}$ as carrier gas). Two methods have been established: a fast one ( $28 \mathrm{~min}$ analysis) which gives a rapid overview of the conversion of the cis/trans decalin and of the stability of the catalysts and a slow one (4h15) adapted from Ref. [24].This online analysis provides decalin conversion by measuring the by-pass cis + trans decalin peaks area, and the cracking products distribution. Contact time was varied in order to compare selectivities at close conversion levels.

$$
\mathrm{x}_{\mathrm{dec}}=\frac{\left(\operatorname{Dec}_{(\text {by-pass }}\right)^{\left.-\mathrm{Dec}_{(\text {out }}\right)}}{\operatorname{Dec}_{(\text {by-pass })}} \%
$$

Cracking selectivity is also calculated, in order to include light (gaseous) products in the mass balance. The cracking product family consists of $\mathrm{C}_{1}-\mathrm{C}_{9}$ compounds; $n$-nonane retention time has been used to mark the division between $\mathrm{C}_{10}$ isomers and cracked products (CkP) (Eq.2), this compound being among the last $C_{9}$ to elute from the reactive mixture of decalin ringopening reaction products and to be unambiguously identified. ${ }^{25}$

$$
S_{C k P}=\frac{A_{\text {peaks, } t<\text { nonane }}}{A_{\text {peaks, tot }}}
$$

Reaction rates (mol. $\mathrm{s}^{-1}$. $\mathrm{g}^{-1}$ ) were calculated from the following formula:

$$
\mathrm{r}_{\text {Dec }}=\mathrm{F}_{\mathrm{dec}} \times \frac{\left[-\ln \left(1-\mathrm{x}_{\text {Dec }}\right)\right]}{\mathrm{m}_{\mathrm{cata}}}
$$

where $F_{\text {dec }}$ represent the flow of decalin, $m_{\text {cata }}$ the catalyst mass. The rate of ROP $r_{\text {rop }}$ was the product of $S_{\text {rop }}$ with $R_{\text {dec }}$.

Even if a high resolution column is used in $1 D \mathrm{GC}$, in the $\mathrm{C}_{10}$ zone, co-elution of isomerization and ring-opening products occurs. Therefore, liquids were condensed the exit of the test and analyzed off-line by GCxGC-MS analysis, described in ref [26], for the identification and GCXGC- FID for quantification. An Agilent $6890 \mathrm{~N}$ chromatograph equipped with a liquid $\mathrm{N}_{2}-$ cooled loop modulator ZX1 (Zoex Corporation) was connected either to a mass detector (Agilent 5975B, mass range: $50-300 \mathrm{~g} / \mathrm{mol}$, up to $22 \mathrm{scans} / \mathrm{sec}$ ) or a flame ionization detector (FID). Besides cracking products, decalin conversion with bifunctional catalysts lead to several 
product families such as ring-opening, isomerization and dehydrogenation families, and combinations of them. The five dominant ones being correspond to:

- 1ROP: 1-ring-opening products, $\mathrm{C}_{10}$ alkyl-mononaphthenes;

- AROP: aromatic 1-ring-opening products, i.e. $\mathrm{C}_{10}$ alkyl-benzenes;

- 2ROP: 2-ring-opening products, i.e. $\mathrm{C}_{10}$ paraffins;

- SkIP: decalin skeletal isomerization products, i.e. $\mathrm{C}_{10}$ alkyl-dinaphthenes;

- DHP: Dehydrogenation products, which consist of all C10 unsaturated products except AROPs (tetralin, naphthalene, methyl-indans...).

Considering $\mathrm{C}_{10}$ compounds, the dominant ones are isomers (SkIPs) and ring-opening products (ROPs) with a small contribution of 2 ROPs, those families being well discriminated by comprehensive GC [27]. Considering that the C10 compounds have the same response factor for FID, the ROP selectivity $S_{\text {rop }}$ was obtained from the quantification C10 isomers whose identification have been described in detail in Ref [28]. Thus, 24 SKiPs, 29 1ROPs and 11 2ROPs compounds have been identified. The complexity of the analysis and coelution in the first column dimension is leveled up by GCxGC. This is illustrated by Figure 5 . where the three families of isomers can be distinguished by three well separated lines of compounds (Top SKiP, middle 1ROP, bottom 2ROP).

Rate of conversion on decalin and ring opening activities of the series of TMS/HY samples are summarized in Table 2. WHSV, indicated in Figure 6, were varied in order to get close conversion levels. Concerning chromium sulfide, the activity was close to that of HY support alone and was no further considered even if the presence of chromium sulfides induced a better stability of the catalysts. Up to $20 \%$ of ROP products can be obtained for the two most active systems Ru and Ir sulfides on HY zeolite nearly twice more active for ROP production than Re and Rh sulfides.

Even if the dispersion is poor for $\mathrm{NiSx} / \mathrm{HY}$, this catalyst exhibits interesting properties. Whereas decreasing the metal loading to $1 \mathrm{wt} \%$ was found to slightly impact the performances of RuS $2 / \mathrm{HY}$ catalysts [16], it has a drastic impact with Ni loading, by decreasing the activity 6 times and leading to a much higher cracking as well as increase of dehydrogenated products, as illustrated by Figure 7. This is clearly indicating a lack of hydrogenation properties and the importance of the balance between the two catalytic functions. 


\section{Mechanism of SRO on TMS/HY catalysts}

Comprehensive GCxGC allows to investigate in detail the evolution of families of products with increasing as well as to describe each compounds of the three C10 families produced during the conversion of decalin in the presence of $\mathrm{H}_{2} \mathrm{~S}$. Figure 8. illustrates the evolution of these products with increasing conversion, cracking products are also added. From these data, a simple consecutive reaction scheme can be proposed (fig 7. left).

This scheme demonstrates that whatever the TMS/HY catalysts used, the mechanism seems to be mainly driven by the acidity of the zeolite as it has been observed either when Ir is poisoned by a small partial pressure of $\mathrm{H}_{2} \mathrm{~S}$ [32] or on $\mathrm{RuS}_{2} / \mathrm{HY}$ [16]. As compared to Ir metal based catalysts in the absence of $\mathrm{H}_{2} \mathrm{~S}$, where the hydrogenolytic properties of the metallic phase lead directly to a high selectivity in ROP products [5], we can conclude that no TMS can hardly achieve direct hydrogenolysis in a mechanism similar to the one observed on metals. Slight differences observed on the selectivity distribution might indicate, however, some specific contribution of Ir or Ru sulfides for instance. Our previous study on RuS2 deposited on different zeolites revealed the necessity of using a strongly acidic zeolite. Comprehensive GC provide a unique insight in the evolution of each compounds of the isomerized families. Thus, Figure 8.a) describes the evolution of major SkIP products with the decalin conversion. The so-called [4.3.0] group is the major product of SKiP family further converted into [3.3.0] , [3.2.1] and [2.2.2/[2.2.1] groups decreasingly. A minor isomerization route is observed for [3.3.1], [5.3.0] groups and BCP as well as spirodecane (not mentioned here), see Figure $8 b$ ). The classification into isomerizations of type $A$ and type $B$ is nowadays well accepted. In type $A$ isomerizations, the number of branchings in the molecule remains constant, whereas in type $B$ isomerizations it increases or decreases. Type $A$ isomerizations are considered on metal catalysts as much faster than those of type $B$, and there are fundamental differences in the mechanisms at the level of carbocations: while type $A$ rearrangements occur via a sequence of classical hydride and alkyl shifts, type $B$ rearrangements proceed via non-classical protonated cyclopropanes. Thus, the main route passes through type $B$ isomerization (branching) as mentioned in the scheme whereas type $A$ isomerization is less favoured. This is the opposite of what has been observed on noble metal based catalysts Ir or Pt on zeolites or silica [5,24]. This mechanism on metals is consistent with the formation of the most expected stable tertiary carbenium. Obviously in this work involving TMS/Y catalysts and decalin reactant, secondary carbenium tend to be favoured.

Based on the Kubicka et al. mechanism [35], a detailed reaction scheme (scheme 1) of the conversion of decalin into other $\mathrm{C}_{10}$ compounds can be proposed from the molecular analysis obtained from comprehensive GCxGC. Since ROP are formed from these isomers issued from these two routes, short chains ROP (originated from isomers of B mechanism) are the main compounds of ROP family whereas long chain ROP (favoured by A route) are in a minor content, as illustrated by Figure $8 \mathrm{c}$. The minor contribution of long chains also 
confirms that the different TMS can hardly open the decalin by itself as it has been observed on Ir metal. Considering these evolutions a general reaction scheme can be proposed evidencing the main and minor routes of the reaction (Scheme 1)

The products distribution of the different TMS/HY are very close and if we go in the detail of the products these distributions do not differ much as illustrated by figure 10.

\section{Ternary sulfides on zeolite: $\mathrm{NiRuS}_{2} / \mathrm{HY}$ and $\mathrm{NiRhS}_{4} / \mathrm{HY}$}

The promotion of the lamellar sulfides $\left(\mathrm{MoS}_{2}, \mathrm{WS}_{2}\right)$ by $\mathrm{Co}$ and $\mathrm{Ni}$, in the form of the so called "CoMoS" phase, originates from the decoration of the slabs of the lamellar phase. However, this type of phase cannot be obtained on HY zeolites. Alternative synergetic effects can be reached by using either solid solutions [18] of TMS or well defined ternary compounds $[19,29]$. The composition of mixed NiRuS and NiRhS catalysts on HY zeolite, investigated in this section, are summarized in Table 3. The objective was the preparation on the zeolite of a solid solution in the case of $\mathrm{Ni}_{0.5} \mathrm{Ru}_{0.5} \mathrm{~S}_{2}$ or a ternary sulfide phase $\mathrm{NiRh}_{2} \mathrm{~S}_{4}$.

TEM images associated with EDS demonstrated in the case of NiRuS/HY catalyst the presence of particles with an average size of $5.5 \mathrm{~nm}$ with a $\mathrm{Ni} / \mathrm{Ru}$ composition close to the expected value of the solid solution

In the case of NiRhSx, sample is more heterogeneous with particles in the range of $5 \mathrm{~nm}$ with the composition on the particles close to the expected one but also a few large NiSx particles of $20 \mathrm{~nm}$.

\section{Performances of the ternary systems}

Figure 13. Compares the family distributions of binary and ternary sulfides on HY support at close conversion levels by changing contact time. The ternary sulfide compounds allow to reach a similar conversion $20^{\circ} \mathrm{C}$ below the individual sulfides indicating the benefit of the formation of the ternary phase. This is illustrated also by Figure 14. which provides the intrinsic and specific rates of decalin conversion and ring opening formation. Activation energy on $\mathrm{RuS}_{2} / \mathrm{HY}$ catalysts was determined $\mathrm{Ea}=111 \mathrm{KJ} / \mathrm{mol}$ and assuming that the mixed $\mathrm{NiRuS}_{2} / \mathrm{HY}$ catalysts exhibit a similar behavior, the synergy factor is estimated to be close to 3. This synergy can be attributed to the formation in the solid solution of pyrite structure of $\mathrm{NiRuS}_{2}$ of a more favourable M-S bond strength. The best performances were obtained with $\mathrm{NiRuS}_{2}$ system which leads to an enhancement of decalin conversion as well as ring opening rate. 


\section{Conclusions}

The bifunctional TMS/HY catalyst can lead to efficient systems than can convert decalin below $250^{\circ} \mathrm{C}$, in the presence of $\mathrm{H}_{2} \mathrm{~S}$, through a mechanism driven by isomerisation reactions, probably governed by the acid sites of the zeolite and stabilized by the hydrogenation/dehydrogenation functions of the TMS. In fact, comprehensive GC evidences that type $B$ isomerization constitutes the main pathway of the consecutive reaction and type A, a minor pathway. These isomerization leads to a large number of skeletal isomerization products which are further converted into ring opening products. The screening of TMS reveal the good performances of noble metal based sulfides as well as interesting properties of $\mathrm{Ni}$ sulfide even if the dispersion of this phase needs to be improved. The combination of the TMS with HY zeolite can modulate the acidic properties and has a strong impact on the catalytic activity but the products distributions are almost similar. Ternary metal sulfides can also promote by synergetic effects the activity and ring opening. Thus, SRO can be observed even at $220^{\circ} \mathrm{C}$. Therefore, TMS/HY can perform SRO in the presence of $\mathrm{H}_{2} \mathrm{~S}$ under relatively soft conditions.

\section{Acknowledgements}

N. C. and E. B. thanks ENI for financial support.

\section{References}

[1] N.Choudhary,; D. N. Saraf, Ind. Eng.Chem. Prod. Res. Dev. 1975, 14 (2), 74-83.

[2] F.Bertoncini, A. Bonduelle-Skrzypczak, J. Francis and E. Guillon E. Chap 3.4 of Catalysis by transition metal sulfides H. Toulhaot et P. Raybaud Ed. Technip, Paris 2013

[3] R.C. Santana, P.T. Do, M. Santikunaporn, W.E. Alvarez, J.D. Taylor, E.L. Sughrue, D.E. Resasco, Fuel 85 (2006) 643-656.

[4] J. Weitkamp, ChemCatChem 4 (2012) 292.

[5] S. Rabl, A. Haas, D. Santi, C. Flego, M. Ferrari, V. Calemma, J. Weitkamp, Appl. Catal. A 400 (2011) 131.

[6] S. Rabl, D. Santi, A. Haas, M. Ferrari, V. Calemma, G. Bellussi, J. Weitkamp, Microporous Mesoporous Mater. 146, (2011) 190.

[7] S. Nassreddine, S. Casu, J. L. Zotin, C. Geantet and L. Piccolo, Catal. Sci. Technol. 1 (2011) 408.

[8] L. Piccolo, S. Nassreddine, G. Toussaint, C. Geantet, J. Chromatogr. A 1217 (2010) 5872-5873

[9] D. Eliche-Quesada, J. Mérida-Robles, P. Maireles-Torres, E. Rodríguez-Castellón, G. Busca, E. Finocchio, A. Jiménez-López, J. Catal. 220 (2003) 457-467.

[10] K. Sato, Y. Iwata, Y. Miki, and H. Shimada, J. Catal. 186 (1999) 45-46.

[11] L. Wang, B. Shen, F. Fang, F. Wang, R. Tian, Z. Zhang, L. Cui, Catal. Today 158 (2010) 343-347.

[12] L. Di Felice, N. Catherin, L. Piccolo, D. Laurenti, E. Blanco, E. Leclerc, C. Geantet, V. Calemma, Appl. Catal. A 512 (2016) 43.

[13] Y. Wang, B. Shen, L. Wang, B. Feng, J. Li, Q. Guo, Fuel Process. Technol. 106 (2013) 141-148

[14] T.A. Pecoraro, R.R. Chianelli, J. Catal. 67 (1981) 430.

[15] M. Lacroix, N. Boutarfa, C. Guillard, M. Vrinat, M. Breysse, J. Catal. 120 (1989) 473. 
[16] N. Catherin, E. Blanco, L. Piccolo, D. Laurenti, F. Simonet, C. Lorentz, E. Leclerc, V. Calemma, C. Geantet, Catal. Today 323 (2019) 105-111.

[17] N. Guernalec, T. Cseri, P. Raybaud, C. Geantet, M. Vrinat Catal. Today 98 (2004) 61

[18]. A. De los reyes, M. Vrinat, C. Geantet, M. Breysse, and J. Grimblot, J. Catal. 142, (1993) 455

[19] H. Yasuda, C. Geantet, P. Afanasiev, M. Aouine, T. Epicier, and M. Vrinat, New J. Chem. 26, (2002) 1196

[20] D. Laurenti, K. T. Ninh Thi, N. Escalona, L. Massin, M. Vrinat, F. J. Gil Llambias, Catal. Today 130 (2008) 5055

[21 ] N. Guernalec, C. Geantet, P. Raybaud, T. Cseri, M. Aouine and M. Vrinat, Oil \&Gas Scien. Tech. 61 (2006) 515-525

[22] F. Jellinek Acta Cryst. 10 (1957) 609-619.

[23] C. A. Emeis, J. Catal. 141 (1993) 347

[24] A. Haas, S. Rabl, M. Ferrari, V. Calemma, and J. Weitkamp, Appl. Catal. A 97 (2012) 425.

[25] S. Rabl, PhD Universität Stuttgart (2011)

[26] G. Toussaint, C. Lorentz, M. Vrinat, C. Geantet, Anal. Methods 3 (2011) 2743.

[27] L. Piccolo, S. Nassreddine, G. Toussaint and C. Geantet, J. Chromatogr. A, 1217 (2010) 5872.

[28] E. Blanco, L. Di Felice, N. Catherin, L. Piccolo, D. Laurenti, C. Lorentz, C. Geantet, V. Calemma, Ind. Eng. Chem. Res. 55 (2016) 12516.

[29] P. Afanasiev, I. Bezverkhyy Applied Catal. A 322 (2007) 129-141 


\section{TABLES}

Table 1- Metal loadings and sulfur contents of monometallic TMS/Y catalysts

\begin{tabular}{|c|c|c|c|c|}
\hline Catalyst & $\begin{array}{c}\text { M loading } \\
\text { wt\% }\end{array}$ & $\begin{array}{c}\text { S loading } \\
\text { wt } \%\end{array}$ & $\begin{array}{c}\mathrm{S} / \mathrm{M} \\
\mathrm{mol} / \mathrm{mol}\end{array}$ & $\begin{array}{c}\text { Metal atoms } / \mathrm{g} \\
10^{19}\end{array}$ \\
\hline $\mathrm{ReS}_{\mathrm{x}} / \mathrm{HY}$ (IWI) & 3.1 & 1.4 & 2.6 & 10.0 \\
\hline $\mathrm{RuS}_{x} / \mathrm{HY}$ (IE) & 2.8 & 2.6 & 2.9 & 16.7 \\
\hline $\mathrm{RhS}_{\mathrm{x}} / \mathrm{HY}$ (IWI) & 2.1 & 1.1 & 1.6 & 12.3 \\
\hline $\mathrm{IrS}_{x} / \mathrm{HY}$ (IWI) & 2.2 & 2.0 & 5.6 & 6.9 \\
\hline $\mathrm{CrS}_{\mathrm{x}} / \mathrm{HY}(\mathrm{IWI})$ & 2.1 & 1.8 & 1.4 & 24.3 \\
\hline $\mathrm{NiS}_{\mathrm{x}} / \mathrm{HY}$ (IWI) & 3.1 & 3.6 & 2.1 & 31.8 \\
\hline $\mathrm{NiS}_{\mathrm{x}} / \mathrm{HY}$ (IWI) & 0.9 & 1.5 & 2.9 & 9.23 \\
\hline
\end{tabular}

Table 2: Rate of conversion and ring-opening activities of noble TMS/HY catalysts at $240{ }^{\circ} \mathrm{C}$, in the presence of $0.8 \% \mathrm{H}_{2} \mathrm{~S}$ at $5 \mathrm{MPa}$.

\begin{tabular}{|l||c|c|c||c|c|}
\hline Catalyst & $\begin{array}{c}\mathbf{X}_{\text {dec }} \\
\%\end{array}$ & $\begin{array}{c}\mathbf{r}_{\text {dec }} \\
10^{-8} \text { mol/(g.s) }\end{array}$ & $\begin{array}{c}\mathbf{r}_{\text {dec }} \\
10^{-3} \text { molecule/(atom.s) }\end{array}$ & $\begin{array}{c}\mathbf{r}_{1 \text { ROP }} \\
10^{-8} \text { mol/(g.s) }\end{array}$ & $\begin{array}{c}\mathbf{r}_{1 \text { RoP }} \\
10^{-4} \text { molecule/(atom.s) }\end{array}$ \\
\hline $\mathrm{ReS}_{\mathrm{x}} / \mathrm{HY}$ & 33 & 43 & 26 & 5 & 3 \\
$\mathrm{RuS} / \mathrm{HY}$ & 38 & 76 & 28 & 14 & 10 \\
$\mathrm{RhS} / \mathrm{HY}$ & 34 & 87 & 37 & 7 & 7 \\
$\mathrm{IrS} / \mathrm{HY}$ & 33 & 107 & 66 & 14 & 12 \\
$\mathrm{NiS} \mathrm{x} / \mathrm{HY}$ & 46 & 66 & 12 & 5 & 1 \\
\hline
\end{tabular}


Table 3. Metal loading and sulfur content of bimetallic TMS/Y catalysts

\begin{tabular}{|l|c|c|c|c|c|}
\hline Catalyst & $\begin{array}{c}\text { M loading } \\
\mathbf{w t} \%\end{array}$ & $\begin{array}{c}\mathbf{M}_{\mathbf{1}} / \mathbf{M}_{\mathbf{2}} \\
\mathbf{m o l} / \mathbf{m o l}\end{array}$ & $\begin{array}{c}\text { S loading } \\
\mathbf{w t} \%\end{array}$ & $\begin{array}{c}\text { S/M } \\
\mathbf{m o l} / \mathbf{m o l}\end{array}$ & $\begin{array}{c}\text { Metal atoms/g } \\
\mathbf{1 0}^{\mathbf{1 9}}\end{array}$ \\
\hline NiRuS $/ \mathrm{HY}$ & $\mathrm{Ni}: 1.1$ & $51 / 49$ & 3.8 & 3.3 & 22.0 \\
$\mathrm{Ru}: 1.8$ & $\mathrm{Ni}: 1.1$ & $58 / 42$ & 3.0 & 4.2 & 19.5 \\
\hline $\mathrm{NiRhS}_{\mathrm{N}} / \mathrm{HY}$ & $\mathrm{Rh}: 1.4$ & & & & \\
\hline
\end{tabular}




\section{FIGURES and SCHEMES}

Figure 1 TEM images, particle size distributions of monometallic and $\mathrm{S} / \mathrm{M}$ atomic ration determined from EDX of TMS/HY fresh catalysts.

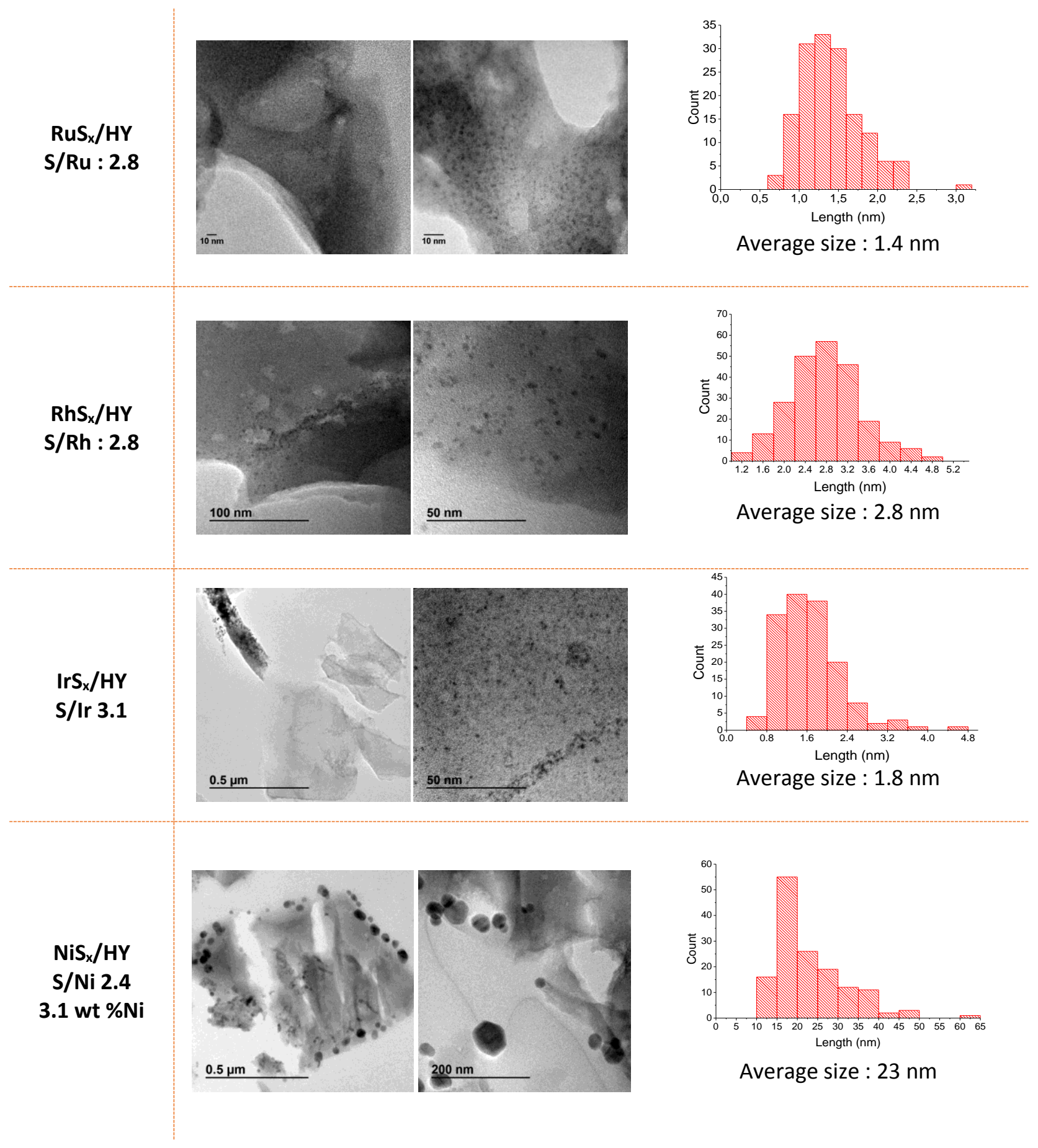




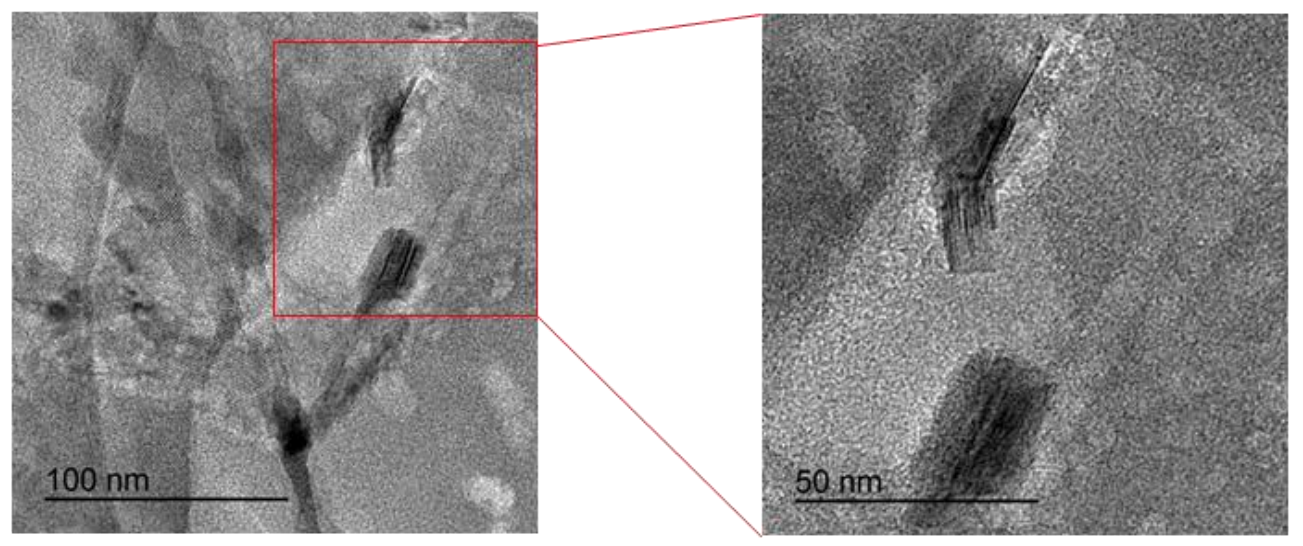

Figure 2 TEM images of the $\mathrm{Cr}_{2} \mathrm{~S}_{3} / \mathrm{HY}$ catalyst sulfided by $15 \% \mathrm{H}_{2} \mathrm{~S} / \mathrm{N}_{2}$ gas mixture.

(S/Cr $=1.6$ from EDX analysis)

Figure 3. IRTF of pyridine adsorption spectra on the series of MS/HY samples after desorption at $150^{\circ} \mathrm{C}$.

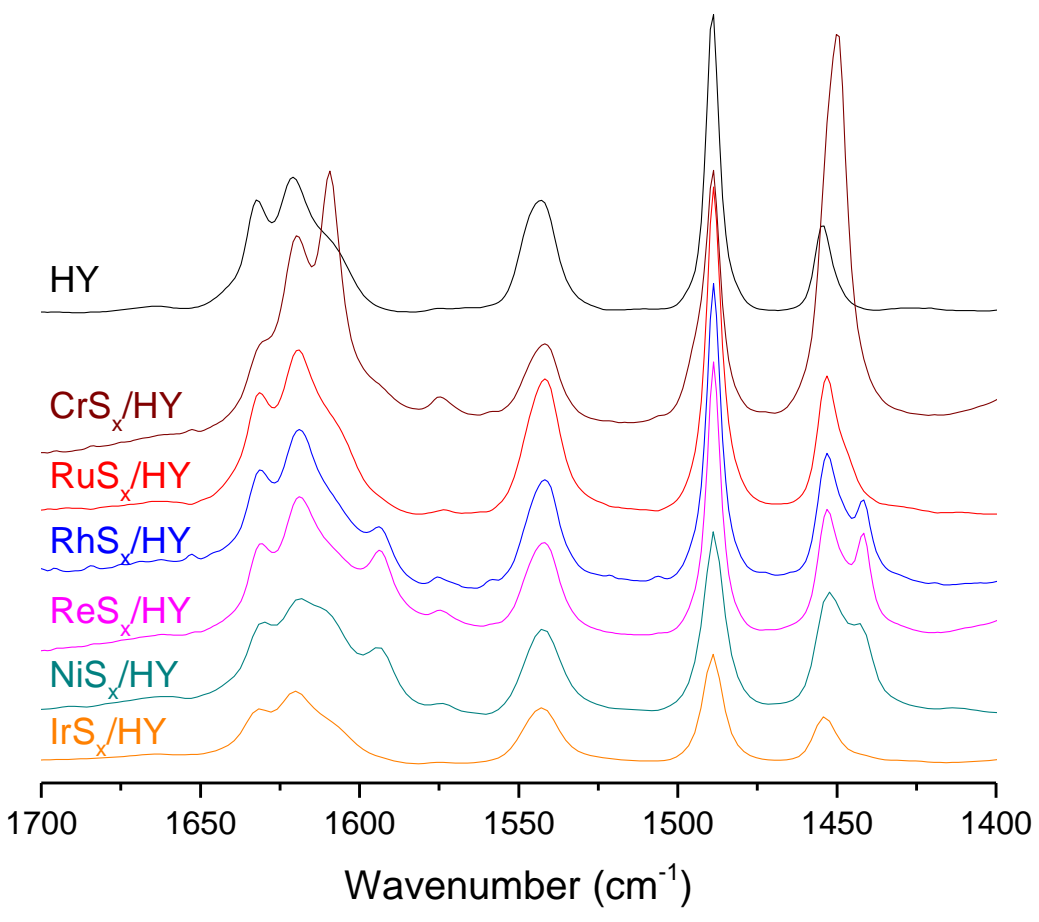



Figure 4 : Brönsted acidity sites of TMS/HY zeolite catalysts determined by IR of pyridine at various desorption temperature.

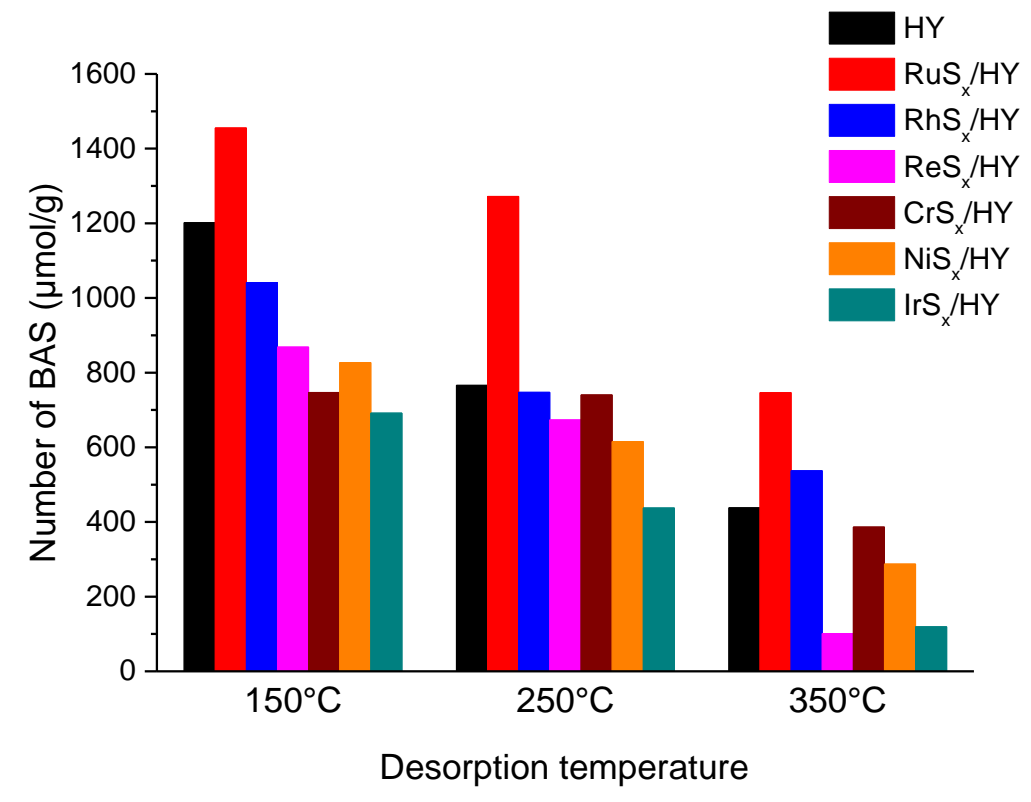


Figure 5. Enhanced view of the C10 isomerized products area of the GCxGC chromatogram of decalin conversion at $240^{\circ} \mathrm{C}$ on a NiRuSx/HY catalyst

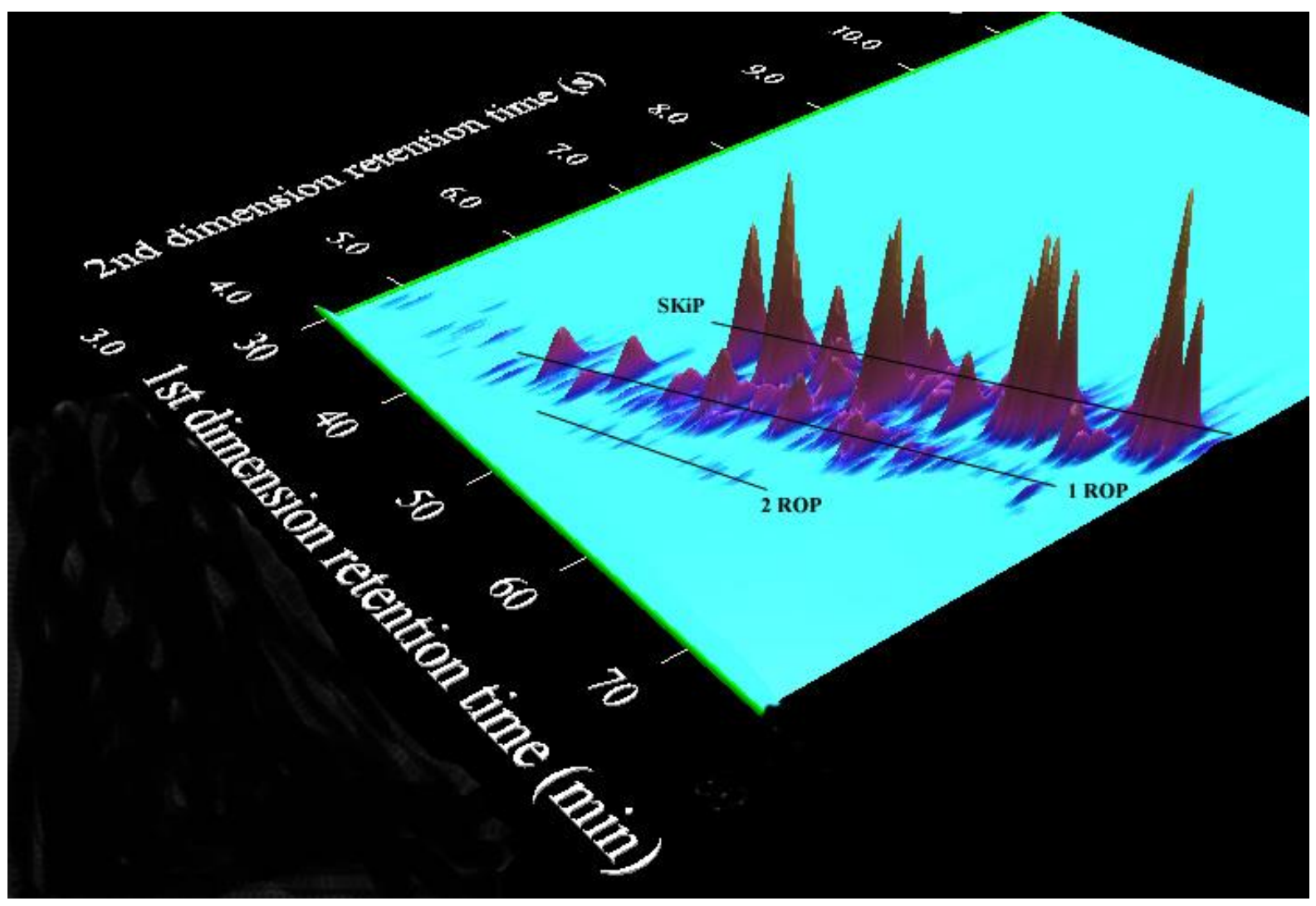


Figure 6. Family selectivities in decalin hydroconversion over noble TMS and NiSx supported on $\mathrm{HY}$ at $240{ }^{\circ} \mathrm{C}$.
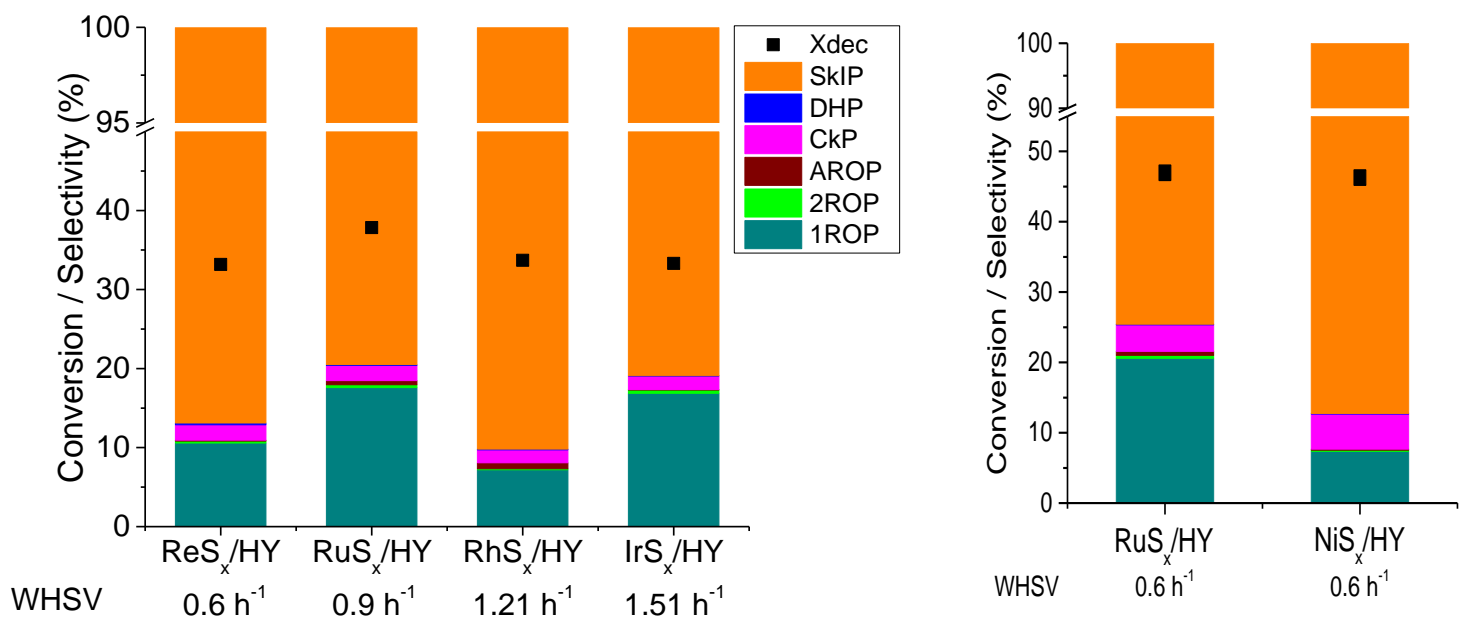
Figure 7. Effect of Ni loading on the products distribution at $240{ }^{\circ} \mathrm{C}$ at circa $25 \%$ conversion.

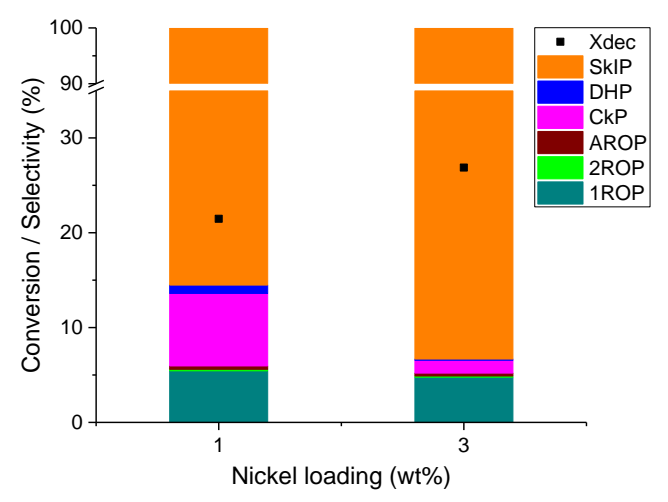


Figure 8. Evolution of the selectivity of family of compounds with conversion for RhSx/HY catalysts, at $240^{\circ} \mathrm{C}$, and indication of the selectivity observed for support alone and $\mathrm{Ru}$ and $\mathrm{Ni}$ sulfides on $\mathrm{HY}$ support (left). Simplified reaction scheme on the left.

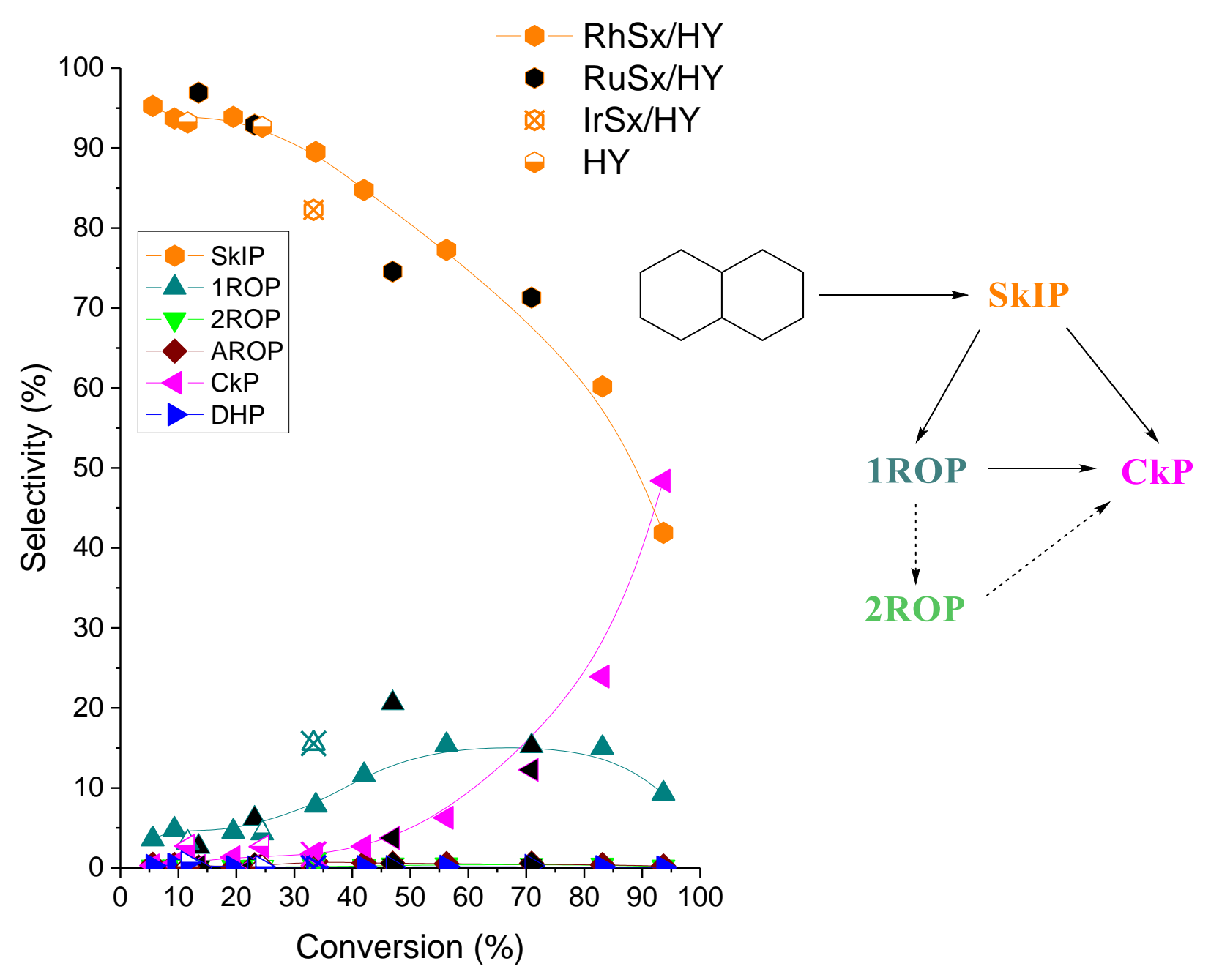


Figure 9. Selectivity of SkIP products and cracking products versus decalin conversion: a) major product (left) and b) minor products (right), c) evolution of ROP products during the conversion of decalin on RhSx/HY catalysts at $240^{\circ} \mathrm{C}$.
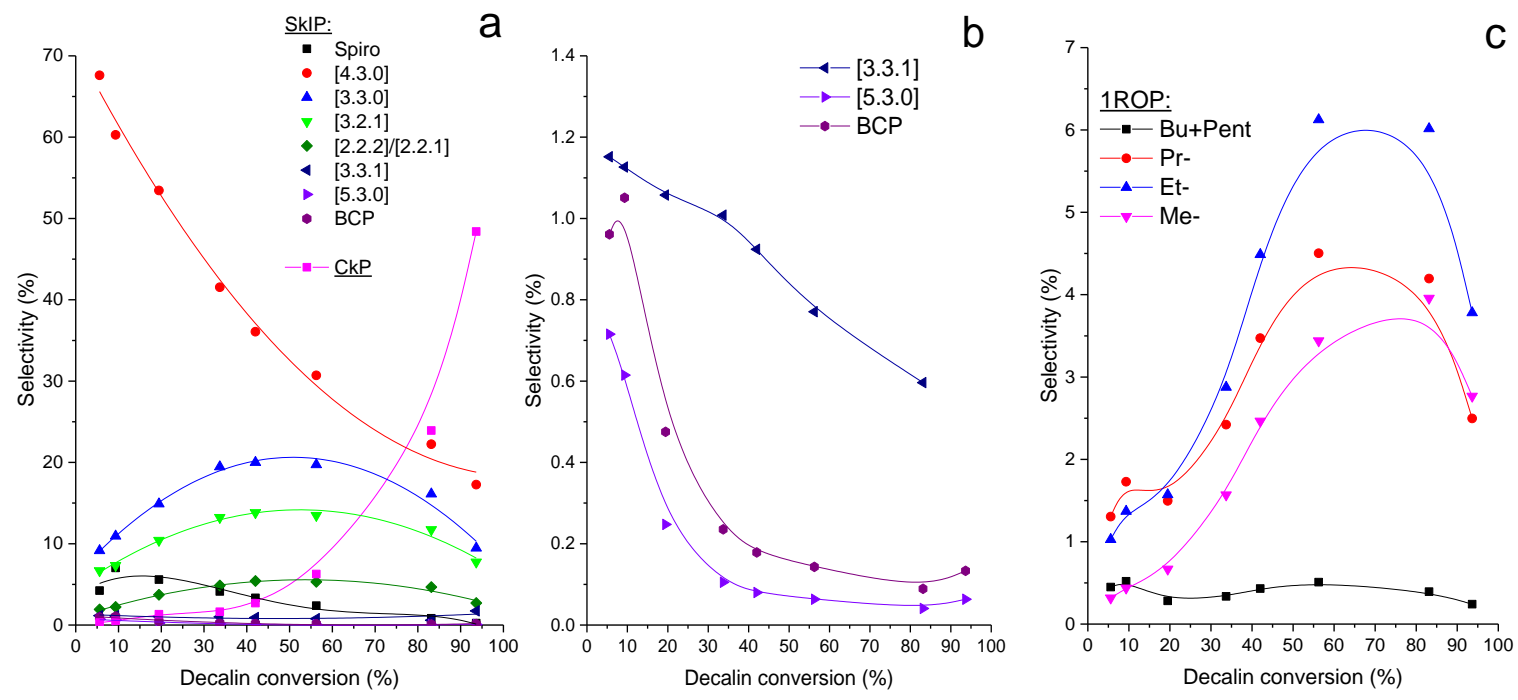
Figure 10. Comparison of the a) SkIP and b) 1ROP distributions between RuS $/ \mathrm{HY}$ and $\mathrm{NiS} \times / \mathrm{HY}$ at $240{ }^{\circ} \mathrm{C}$.

a.

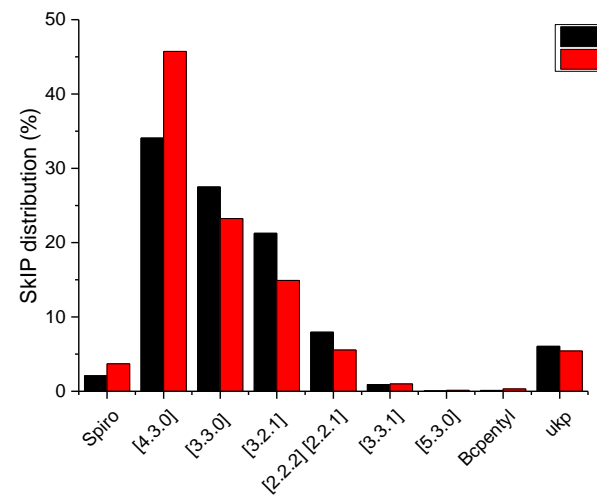

b.

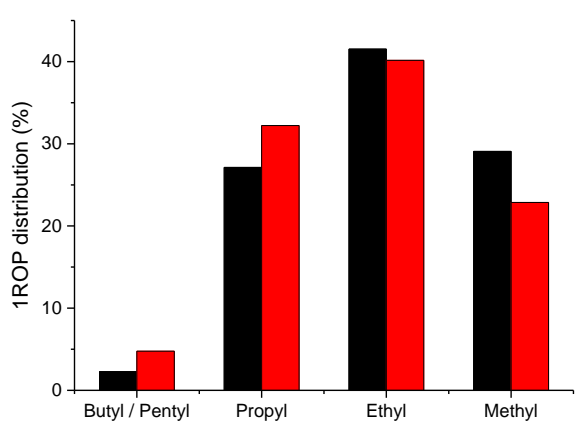


Figure 11. TEM pictures and particle size distribution of NiRuS on HY zeolite.
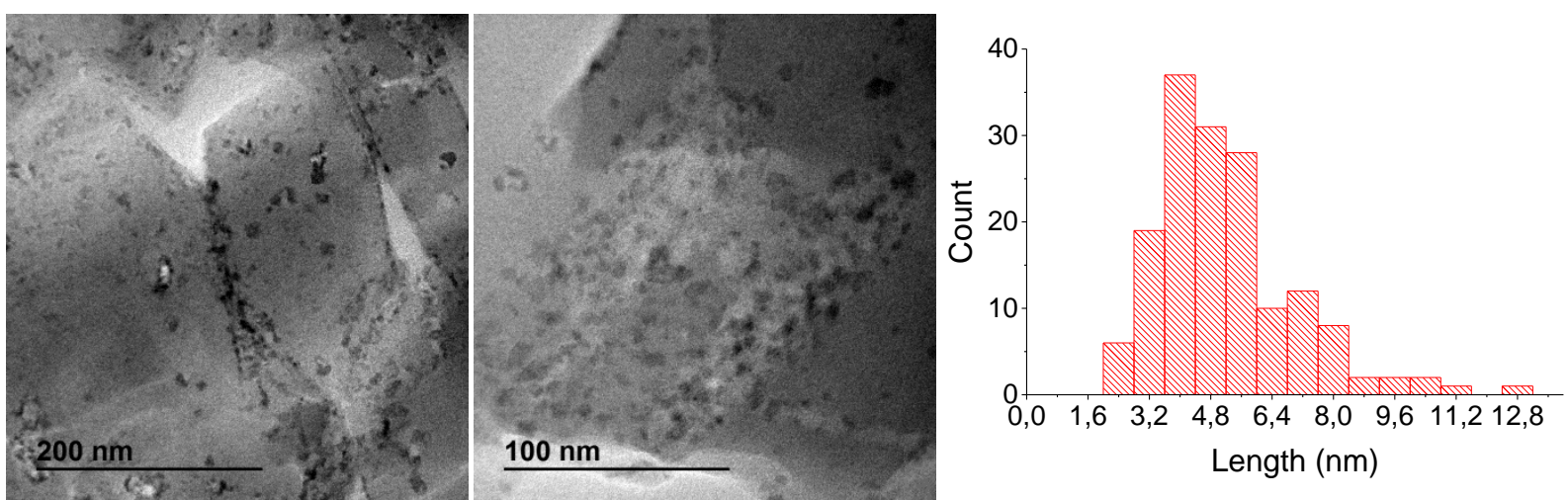

Figure 12. TEM pictures of NiRhSx on HY zeolite.
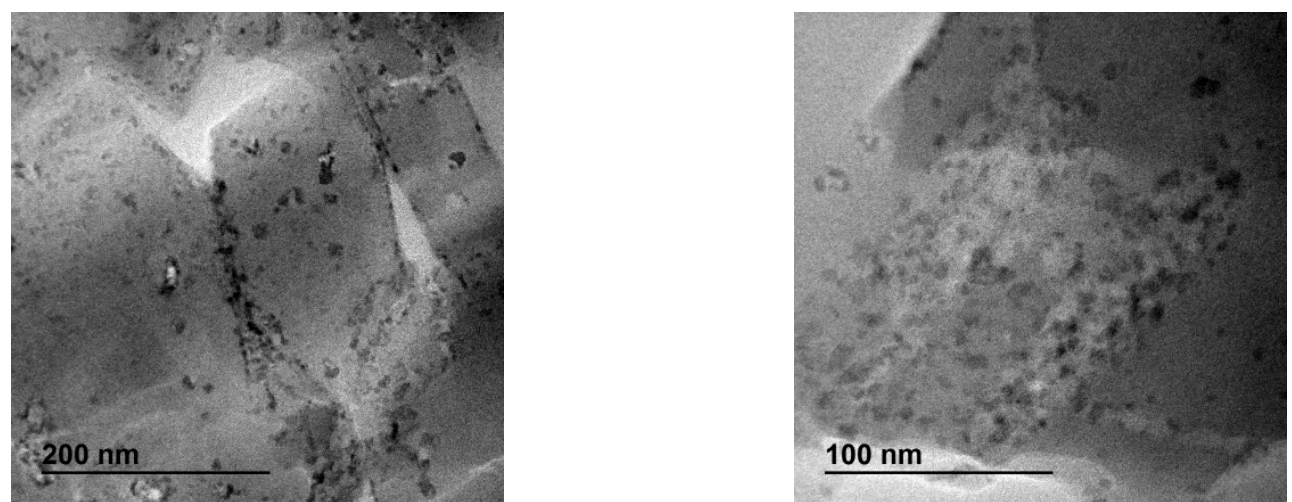
Figure 13. Comparison of the performances of individual and mixed TMS on HY in decalin conversion.

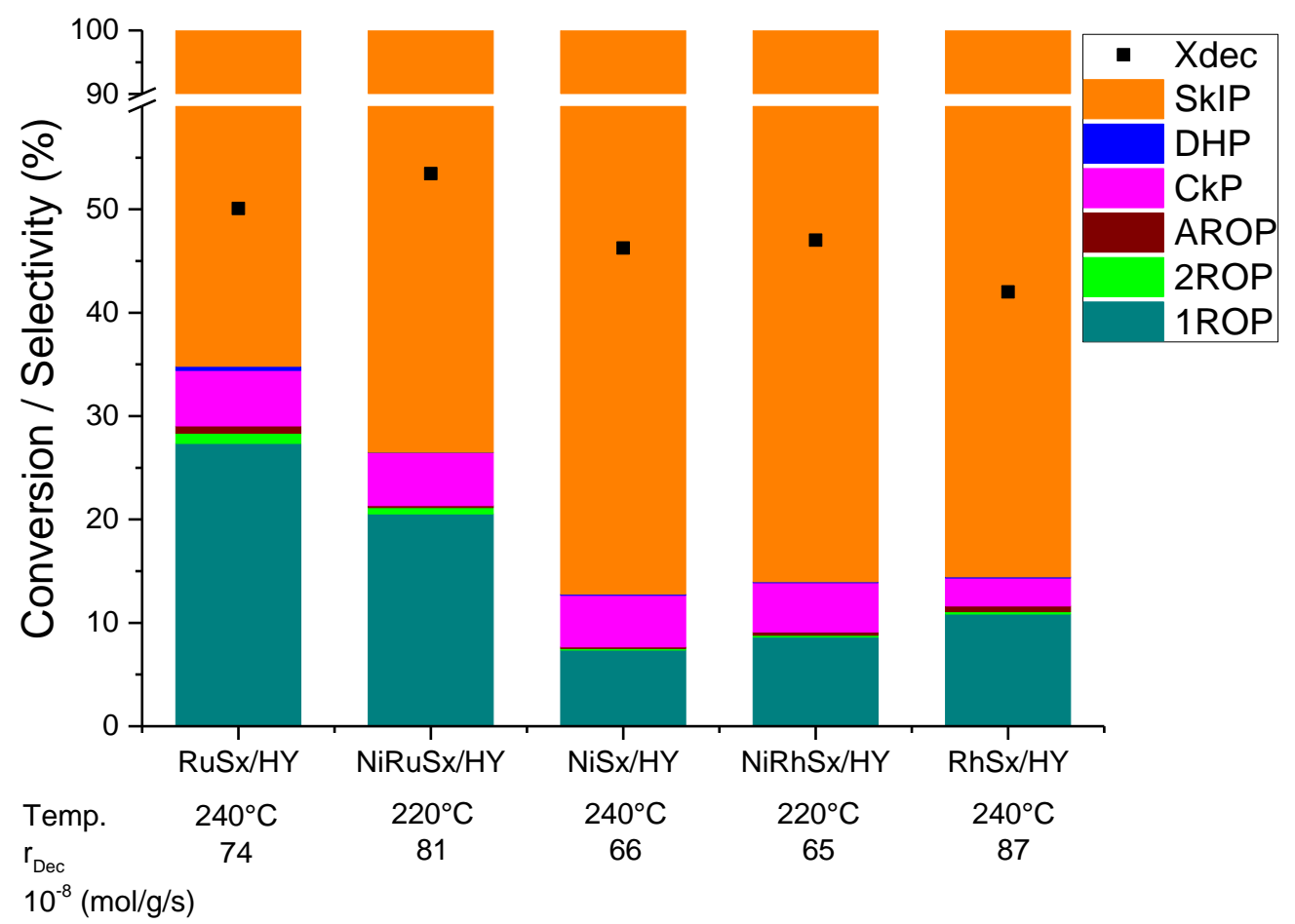

Figure 14. Comparison of specific and intrinsic (per total atom) rates of decalin conversion and ring opening for HY-supported ternary systems and their binary counterparts extrapolated at $240^{\circ} \mathrm{C}$.
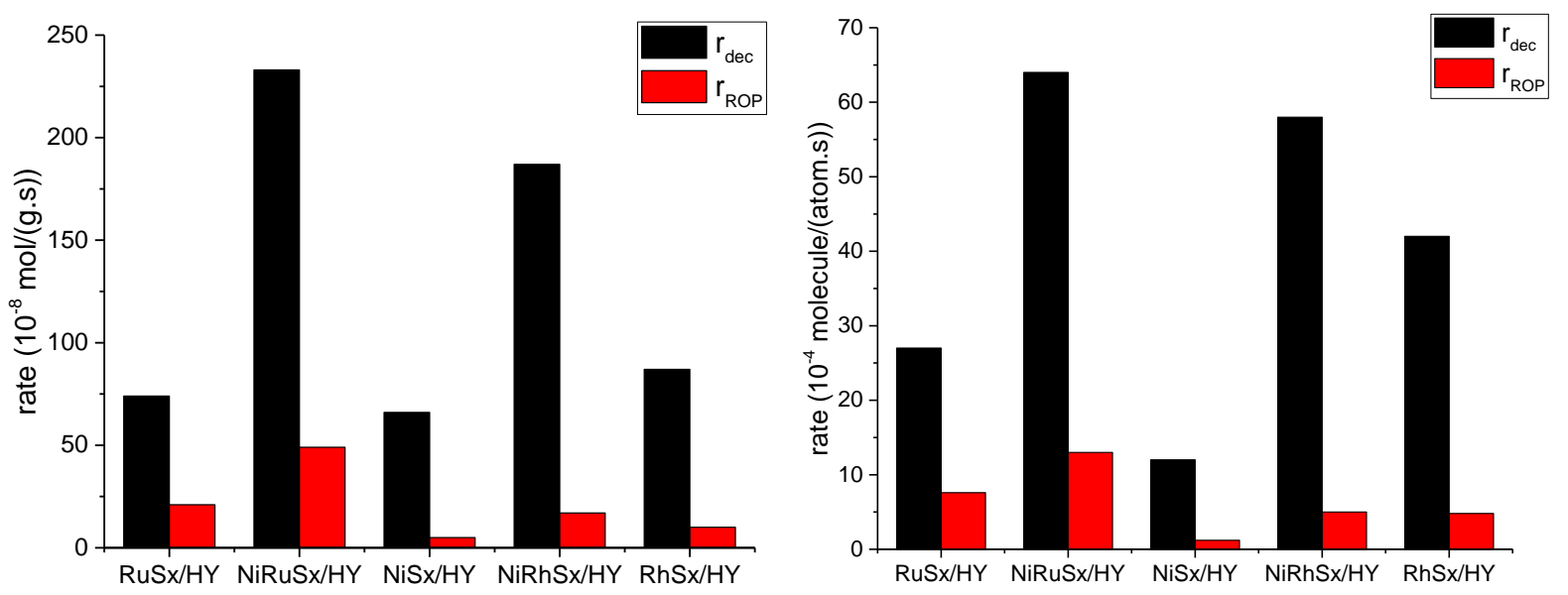
Scheme 1. Reaction scheme of decalin conversion on TMS/HY zeolites, A and B indicates the acidic mechanism.

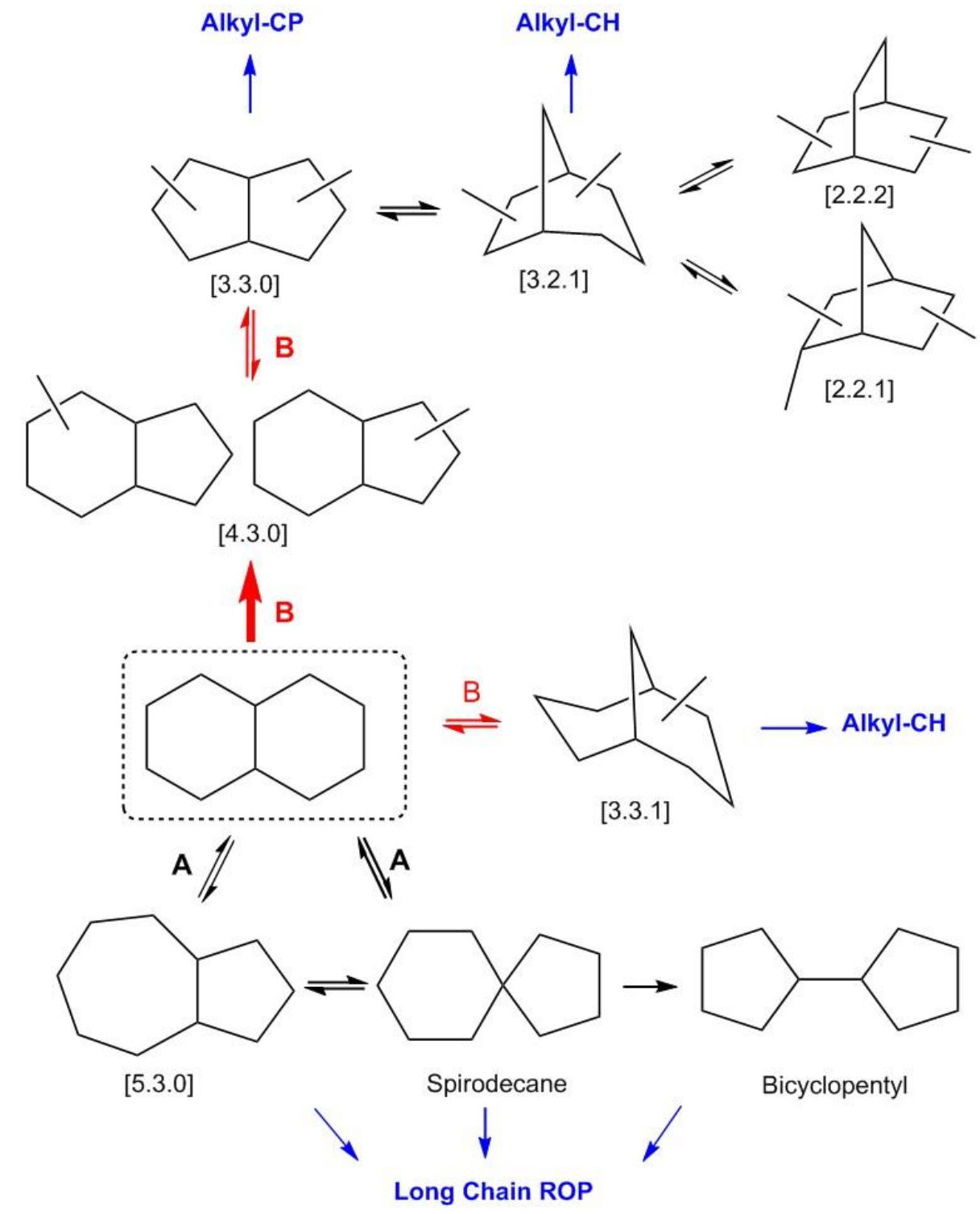

